\title{
UNA NUEVA APUESTA DE LOS CAFETICULTORES CHIAPANECOS. La estrategia del Símbolo de PeQueños Productores
}

\section{A New Challenge for Chiapas's Coffee Growers. The Strategy of the SMall Producers' Symbol}

\author{
Ángeles Tepox-Vivar* \\ Alma Amalia González-Cabañas** \\ DOI: http://dx.doi.org/10.29043/liminar.v19i1.815
}

\begin{abstract}
Resumen: El objetivo del artículo es analizar la potencialidad del Símbolo de Pequeños Productores (SPP) como una opción que permita identificar si este dispositivo de coordinación constituye una opción de mejor participación campesina en cuanto al desarrollo de capacidades y empoderamiento para las organizaciones campesinas. Nos basamos en revisión bibliográfica, análisis de los objetivos y postulados de las iniciativas estudiadas en sus sitios web y material de difusión impreso, así como en trabajo de campo con organizaciones de la región de Los Altos de Chiapas, México, acreditadas con el SPP. La discusión en términos teóricos se basa en las aportaciones desde diversas disciplinas que estudian los intersticios de la globalización como proceso social en una perspectiva múltiple: económica, filosófica, consumo y marketing, movimientos sociales y construcción de confianza.
\end{abstract}

Palabras clave: comercio justo, pequeños productores, cafeticultura, fair trade, procesos de certificación.

Abstract: This article analyzes whether the Small Producers' Symbol (SPP in its Spanish initials), is a method that helps to determine whether this coordinating mechanism is a better option for peasant participation in terms of capacity building and empowerment for peasant organizations. We based our work on a review of the literature, an analysis of the objectives and premises of the initiative as outlined on the SPP website and printed materials, as well as on fieldwork with SPP-accredited organizations in the Altos region of Chiapas. Theoretical discussion is based on contributions from various disciplines that study the interstices of globalization as a social process from multiple perspectives: economic, philosophical, consumption and marketing, social movements, and confidence building.

Keywords: small producers, certification processes, coffee production, fair trade.

\footnotetext{
* Ángeles Tepox Vivar. Doctora en Estudios Regionales por la Universidad Autónoma de Chiapas, México. Investigadora independiente. Temas de especialización: problemas sociales del sector cafetalero y los mercados alternativos, pequeños productores, desarrollo económico. Correo electrónico: tepox.angeles.17@gmail.com. ORCID: https:/ orcid.org/0000-0002-3213-0569

* Alma Amalia González Cabañas. Doctora en Estudios sobre Améri ca Latina por la Universidad de Toulouse Le Mirail, Francia. Investigadora titular B del Centro de Investigaciones Multidisciplinarias sobre
}

Chiapas y la Frontera Sur de la Universidad Nacional Autónoma de México (CIMSUR-UNAM), México. Temas de especialización: desarrollo rural, agricultura orgánica, comercio justo, agricultura campesina. Correo electrónico: agonzale@unam.mx. ORCID: https:/orcid. org/0000-0002-5538-2638

Enviado a dictamen: 12 de febrero de 2020. Aprobación: 20 de mayo de 2020. 


\section{Introducción}

$\amalg$ Comercio Justo (CJ) surge como un esfuerzo ético con miras a generar relaciones comerciales equitativas mediante la construcción de espacios favorables de negociación para los pequeños productores. Su evolución ha permitido ganar espacios en el mercado mundial de café, pero también ha generado inconsistencias entre los principios éticos reivindicados en sus albores y sus actuales estrategias comerciales.

Nosotras planteamos que la evolución del CJ se ha caracterizado por la existencia de una disyuntiva entre los acuerdos solidarios y los mecanismos de mercado. La permanencia en el mercado ha implicado a los actores adaptarse a necesidades con un alto coste: flexibilizar sus principios éticos y, con ello, las reivindicaciones políticas y culturales del CJ.

Precisamente, el dilema entre los acuerdos solidarios y las necesidades del mercado ha generado tensiones entre las diversas facciones que componen el CJ, de tal suerte que privilegiar las ventas del producto coadyuvó a que el movimiento de CJ aceptara la participación de grandes consorcios en los eslabones de la distribución y la torrefacción. ${ }^{1}$ Esta medida, que se manejó discursivamente como una estrategia de posicionamiento comercial, generó rupturas al interior del CJ, y con ello un fuerte cuestionamiento a sus principios éticos.

Tal fue el grado de tensión, que una de las apuestas que plantearon las organizaciones productoras fue la creación de un sello adicional, el Símbolo de Pequeños Productores (SPP). Este se presenta como un espacio de participación efectiva, conducido por y para pequeños productores. Actualmente el SPP agrupa a 120 organizaciones de pequeños productores que se distribuyen en 30 países, y tiene presencia en 50 países consumidores, datos que apuntan su potencial relevancia (SPP, 2019).

La creación del SPP contó con la participación de organizaciones cafeticultoras de México, especialmente de Chiapas. La colaboración de los productores chiapanecos no es fortuita; en primer lugar, México, y particularmente Chiapas, se ha posicionado como uno de los principales productores de café orgánico certificado a nivel internacional, y, en segundo lugar, cerca de 180000 familias chiapanecas dependen de la producción del aromático (Instituto del Café de Chiapas, 2019). Aunada a la importancia histórica de la actividad cafetalera en la entidad, a nivel mundial está cobrando dinamismo la elaboración de productos agroalimentarios certificados, y los pequeños productores son potencialmente protagonistas en estas transformaciones que se experimentan en los mercados.

Este artículo constituye la base teórica reflexiva y los primeros resultados de una investigación ${ }^{2}$ con tres organizaciones de Los Altos de Chiapas que participan en el CJ. El texto se concibe como un recurso que contribuya a la discusión y, en la medida de lo posible, a la toma de decisiones de los cafeticultores indígenas, de manera muy particular a través de los espacios creados por estas iniciativas, como, por ejemplo, en sus sitios web, que incluyen bibliografía académica y de práctica social con distintas posturas críticas. ${ }^{3}$ Igualmente, las asambleas donde participan los representantes regionales de organizaciones campesinas permiten la discusión de posturas críticas sobre la toma de decisiones y el empoderamiento de las organizaciones cafetaleras.

\section{Comercio justo zun nuevo movimiento social?}

En términos conceptuales el CJ comprende un conjunto de principios epistemológicos de orden ético, social y político, cuyo campo de acción son los intercambios de bienes y servicios (Auroi, 2006). Los principios del CJ son: 1) acceso al mercado de los pequeños productores, 2) relaciones comerciales sostenibles y equitativas, 3 ) desarrollo de capacidades y empoderamiento, 4) sensibilización de los consumidores e incidencia política, y 5) Comercio Justo como un "contrato social (Fairtrade International, 2009).

Académicos como Roch y Demers identifican el CJ como parte de los "nuevos movimientos económicos" (2007:91), caracterizados por cuestionar la concepción clásica de las transacciones económicas y por recurrir a prácticas como boicots, certificación e inversión socialmente responsable. Estos académicos consideran que, si bien estos movimientos no son propiamente una 
nueva generación, sí emplean una nueva modalidad de acción dado el uso de herramientas económicas (Roch y Demers, 2007).

En esa misma línea de argumentación, hay académicos (Gendron, 2001; Micheletti, 2003; Otero, 2006) que identifican el CJ entre los movimientos sociales que utilizan el estatus económico del consumidor con fines de presión sociopolítica. Las personas que conforman estos movimientos se apropian de los mecanismos económicos y los moldean en función de sus valores. Por tanto, la incursión de los movimientos sociales en el campo económico refrenda la redefinición de las transacciones económicas, tanto en términos políticos como sociales. El consumo responsable permite influir sobre las prácticas más allá de la jurisdicción nacional en la que se mueve el ciudadano, e impone una verdadera globalización de la movilización social. No es el consumidor quien toma el lugar del ciudadano, sino que es el ciudadano quien se infiltra detrás del consumidor (Gendron, 2008).

El CJ se inscribe en el campo de influencia del consumo responsable y usa la economía con fines sociales y políticos para coadyuvar a la estructuración ética del mercado, imponiendo un marco de referencia al que serán irremediablemente confrontados los actores económicos tradicionales (Gendron, Bisaillon y Otero, 2009). Las autoras concebimos este tipo de iniciativas de mercado como un movimiento social, entendido este, primeramente, como acción colectiva. Consideramos que corresponden a lo que se ha dado en llamar "nuevos movimientos sociales", en tanto que se define el movimiento social como una conducta colectiva portadora de un proyecto de sociedad alternativo, en una lucha que no va dirigida contra el Estado, sino contra un adversario de clase. Es así como el movimiento social es un actor colectivo que busca adueñarse de los "valores", de las orientaciones culturales de una sociedad, oponiéndose a la acción de un adversario con el que se está vinculado por relaciones de poder (Touraine, 1994).

Los actores que participan en el CJ son consumidores reflexivos que, a diferencia del consumidor hedonista, buscan mediante su compra contribuir a la sociedad. A pesar de la situación desfavorable que enfrenta la agricultura campesina, consumidores y productores, urbanos y rurales, se movilizan para reivindicar las dimensiones éticas, agroecológicas y culturales de los alimentos y apuntalar la economía familiar de los pequeños agricultores. Estos actores tienen como propósito establecer relaciones en las cuales tanto productores como consumidores, de manera colectiva, rediseñen los valores del sistema agroalimentario (Nigh y González, 2015).

La voluntad o el deseo de romper con el mercado conduce a la búsqueda de modelos explicativos con base en sociedades prístinas, tal como las estudiadas por Mauss (2009[1924]). En este sentido, podríamos preguntarnos qué tan factible es explicar el comercio justo a través del don en el sentido maussiano. A nuestro juicio, este planteamiento se encuentra lejos de estar presente en el acto de compra bajo las condiciones del mercado. El don estudiado por Mauss se da en relaciones directas y opera bajo complejos sistemas de reciprocidad, de reconocimiento del uno hacia el otro, en tanto que el CJ ha priorizado la movilización de símbolos no solo como mecanismo de control mercantil, ${ }^{4}$ sino en el sentido de asociar el $\log _{0}{ }^{5}$ con emociones, con un posicionamiento social o con valores éticos que, si bien pueden declararse de solidaridad, no resulta simple distanciarlos de posturas impregnadas del sentido de caridad característico de los valores judeocristianos. Esta consideración nos lleva a citar uno de los pensamientos de Eduardo Galeano para puntualizar la diferencia entre solidaridad y caridad: "A diferencia de la solidaridad, que es horizontal y se ejerce de igual a igual, la caridad se practica de arriba hacia abajo, humilla a quien la recibe y jamás altera ni un poquito las relaciones de poder". 6

Pero quisiéramos señalar de manera más categórica la distancia irreconciliable que existe entre el don y el CJ, inscrito este último en una sociedad de mercado neoliberal. Retomamos por ello la siguiente cita de Dominique Temple ${ }^{7}$ por la agudeza de su pensamiento:

El don impone la necesidad de producción y crea un desequilibrio entre la producción y el consumo a partir del cual, el ciclo económico encuentra una dinámica de crecimiento y una polaridad dialéctica 
que son evidentemente inversas a las de nuestro sistema de producción y allí está la fuente de numerosas confusiones; entonces, el excedente de consumo es de cierta manera el equivalente (antagónico) del plusvalor de nuestro sistema occidental (Temple, 1983:20, traducción propia).

\section{Orígenes y evolución del movimiento: un breve recuento de las iniciativas del CJ}

El surgimiento del movimiento de CJ se sustentó en dos componentes claves: en primer lugar, la reivindicación de principios éticos, principalmente de la solidaridad y la confianza, como base para la construcción de relaciones comerciales justas. Y, en segundo lugar, por la amplia participación de diversas organizaciones de corte religioso, de la sociedad civil y organizaciones ligadas a organismos que promueven el desarrollo económico. Esta vasta base ciudadana protagonizó la construcción de diversas iniciativas con miras a contribuir al progreso social de los pueblos del sur, ${ }^{8}$ para quienes el comercio ha jugado un rol protagónico.

En la medida en que las organizaciones se adaptaban y profesionalizaban en los esquemas de comercialización de productos, los canales de distribución se estructuraban de manera cada vez más sofisticada en los países del norte, particularmente en Europa. Comenzaron entonces a conformarse organizaciones no gubernamentales, denominadas Alternative Trading Organizations (ATO), especializadas en la venta de este tipo de productos. La base social de dichas organizaciones se conforma por grupos políticos y religiosos que comparten un compromiso moral y ético basado en la justicia social, económica y comercial (Faircompanies, 2007).

Ahora bien, en la amplia base de actores que empezaron a configurar los canales de comercialización se observa la imbricación de cuatro raíces principales: por un lado, el movimiento cooperativista junto con el comercio de la caridad y, por otro, el comercio solidario y el comercio de desarrollo (Gendron, Bisaillon y Otero, 2009). Los cooperativistas pioneros cuestionaban el lucro excesivo de los intermediarios y, al mismo tiempo, destacaban la necesidad de transformar la naturaleza de las relaciones comerciales con el objetivo de convertirlas en un medio para que la sociedad civil se organice, de tal suerte que el ciudadano consumidor adquiere conciencia de su capacidad como actor protagónico del cambio social (Malservisi y FaubertMailloux, 2000).

Por otro lado, una gran parte de las organizaciones religiosas han tenido una larga historia de participación en actividades caritativas, y una fracción importante de ellas ha evolucionado a iniciativas de desarrollo social. Al término de la Segunda Guerra Mundial tendieron a caracterizarse por utilizar el modelo de "comercio de caridad" para vender artesanías y otros bienes, con el fin de recaudar fondos para refugiados de guerra y ayuda en casos de desastre (Low y Davenport, 2006).

Durante las décadas de 1960 y 1970, las organizaciones no gubernamentales y las personas con preocupaciones sociales percibieron la necesidad de crear asociaciones que brindaran asesoría, asistencia y acompañamiento a productores desfavorecidos. Estas relaciones se establecieron con el objetivo de construir una mayor equidad en el comercio internacional, y se basaron en la asociación, el diálogo, la transparencia y el respeto entre sus participantes. Así pues, el crecimiento del CJ desde finales de los años sesenta en adelante se asoció principalmente con el comercio de desarrollo. ${ }^{9}$

Otra línea evolutiva del CJ se configuró a partir de filosofías y grupos religiosos que posteriormente se vincularían con diversos movimientos políticos contestatarios respecto a las relaciones comerciales inequitativas, así como con movimientos que reivindicaban estilos de vida alternativos. Y, por último, también se incorporó una rama distinta estructurada en torno a organizaciones en los países del norte para importar bienes de países del sur, arguyendo identidades políticas comunes (Kocken, 2014).

Los decenios de 1980 y 1990 marcan un momento crucial debido a que las diferentes raíces convergen y se consolidan en torno a las ideas de un comercio internacional "justo y equitativo". En este periodo, en naciones como Holanda, Francia y Alemania se logró la consolidación de tres grandes ejes del movimiento: 1) la 
profesionalización de puntos de venta, 2) la incursión de los productos justos en el sector agroalimentario, y 3) la creación del sello justo.

En sus inicios, el CJ se caracterizó por su contenido político y cultural. Paradójicamente, la estructura y sistematización de la venta de los productos eran aspectos menos explotados por las organizaciones. Existían algunas de estas que se encargaban de comercializar los productos, pero se encontraban diseminadas y no compartían una visión ni acuerdos comunes para su funcionamiento y coordinación. Posteriormente, debido a la exitosa aceptación de estos productos, se requirió estructurar y dar coherencia a estos esfuerzos a través de la articulación de redes.

A inicios de los noventa, en Holanda la organización Solidaridad, junto con la organización cafetalera del estado de Oaxaca Unión de Comunidades de la Región del Istmo (UCIRI), crearon el sello Max Havelaar y comenzaron a comercializar productos de esta última en Europa. La recepción positiva del sello provocó el surgimiento de iniciativas similares en los países consumidores, las que en 1997 se agruparon y crearon Fairtrade Labelling Organizations Internacional (FLO) (ver Figura 1). El principal objetivo de esta nueva figura asociativa consistió en unificar criterios y procesos de certificación.

El sentido de institucionalización comenzó a prevalecer, y condujo a que en 2004 FLO se dividiera en dos organizaciones independientes, FLO y FLO-CERT, con miras a separar y transparentar los procesos de definición de criterios y el proceso mismo de inspección y certificación.

De esta manera se fueron profesionalizando las distintas tareas de cada una de las instancias que conformaban la nueva estructura: el buró central de FLO se encargaba de definir los criterios del CJ, con particular énfasis en el fortalecimiento de la capacidad organizativa de los pequeños productores, en tanto que FLO-CERT se dedicaba a inspeccionar y certificar a las organizaciones productoras y comercializadoras, así como también daba seguimiento a los productos certificados (Doppler y González, 2007; Fairtrade International, 2019).
Actualmente, el sistema Fairtrade se rige por la Asamblea General y la Junta. La asamblea está compuesta en partes iguales por redes regionales de las organizaciones de productores ${ }^{10}$ y las organizaciones nacionales de los países consumidores (NFO). Si bien existe esta asamblea, la toma de decisiones se lleva a cabo en el seno de la Junta Directiva de Fairtrade, que es elegida por la Asamblea General e incluye: cuatro miembros propuestos por las tres redes de productores, cuatro miembros nominados por las NFO y tres miembros independientes (Fairtrade international, 2017). En 2011 se experimentó el último cambio relevante en la estructura de FLO, cuando la iniciativa nacional Fair Trade Estados Unidos (FTUSA) anunció la renuncia de sus miembros del sistema Fairtrade Internacional. FTUSA propuso la incorporación de grandes plantaciones y de agricultura por contrato a Fairtrade. La proposición tuvo una recepción negativa por parte de los demás miembros y FTUSA se escindió del sistema Fairtrade (CLAC, 2011).

La propuesta defendida por FTUSA expresa precisamente una inconsistencia con los valores éticos del CJ, en tanto que se involucra con los grandes actores que llevan a cabo prácticas oligopólicas en diversos mercados agroalimentarios, y que justamente han cerrado los espacios de participación a los pequeños productores. A la vez, esta tendencia se perfilaba en los canales alternativos de producción y comercialización ante la incursión de los grandes consorcios alimenticios, aunque hasta ese momento aún no expresaban su interés en participar en los nodos iniciales, es decir, en el cultivo del café directamente. Ahora, estos grandes consorcios buscan participar en canales alternativos mediante la participación directa en el cultivo utilizando sus propios sellos para la comercialización.

\section{El debate en torno a la confianza}

El CJ se sustenta en la confianza del consumidor, quien está dispuesto a pagar un sobreprecio si tiene la certeza de que efectivamente este llegará a los productores marginados. Esa confianza se basa en un proceso sistémico altamente abstracto. El consumidor delega en 
el dispositivo comercial la responsabilidad de definir aquello que remite a la solidaridad social y al desarrollo sustentable de las organizaciones campesinas. Ahora bien, para depositar la confianza en un sistema se precisa que este ofrezca el respaldo de un conjunto de normas y procedimientos emitidos por expertos. Por tanto, la confianza se operativiza mediante procesos de certificación (Doppler y González, 2007).

En el CJ, la certificación establece acuerdos con un contenido político y cultural, y actúa, además, como un mecanismo de mercado. La certificación expresa un conjunto de acuerdos entre los actores que conforman el dispositivo comercial. Particularmente, estos acuerdos van más allá de un convenio comercial, y tienen un significado político y cultural en tanto que los productores, como los consumidores, expresan un cuestionamiento a la forma en que se construyen las relaciones comerciales.

Por consiguiente, la evaluación que realizan los consumidores de los productos que se comercializan en los mercados alternativos no se ajusta necesariamente a los principios que priman en la producción estandarizada. En el mercado convencional el precio, la reputación y la publicidad del producto inciden en la toma de decisiones del consumidor, pero en el caso de los mercados alternativos, debido a las motivaciones éticas y culturales de los consumidores, estos elementos no son funcionales.

Las propiedades que un producto adquiere en un dispositivo de comercialización que opera bajo principios de confianza mutua entre los agentes no son precisamente tangibles, de allí que el consumidor no tenga elementos para evaluar si verdaderamente la "calidad", entendida en este caso como la confianza entre los agentes, está presente o no en el bien adquirido. Es decir, los consumidores por sus propios medios no pueden evaluar si un bien es ecológico o, en su defecto, si cumple con estándares éticos de solidaridad social (Zeithaml, 1981). Por lo tanto, el café comercializado bajo el sello de CJ contiene relaciones de confianza entre productor y consumidor.

En los mercados diferenciados como el CJ, los atributos movilizados no se degustan, no pueden validarse a través de los criterios clásicos de consumo del bien, de modo que los mecanismos de señal de la calidad se vuelven ineficientes o poco creíbles. Por ende, para brindar a los consumidores una fuente de información confiable sobre las características de los productos es necesario e indispensable utilizar "señales" certificadas por terceros, como las etiquetas o "labelizaciones" (Caswell y Mojduszka, 1996:10).

Así, la creación de una etiqueta ha permitido al CJ garantizar la confianza y, con ello, la prevalencia de los valores éticos reivindicados. Una etiqueta no tiene valor a menos que la información ofrecida sea creíble y proporcionada por una fuente confiable. A la par, salvaguardar la confianza requiere a su vez de un método para respaldar/asegurar lo que representa esa etiqueta (Nigh y González, 2015).

Si bien la etiqueta y el proceso de certificación son reconocidos como un mecanismo eficiente de mediación comercial, hay evidencia que sugiere la existencia de una distribución inequitativa del poder de negociación entre las empresas certificadoras y sus contrapartes, lo cual afecta los estándares de calidad. Esto significa que el nivel de certificación ofrecido por los certificadores privados depende de quién tiene el poder de negociación, más que del procedimiento en sí. El agente que tiene el poder de negociación será quien fije los estándares, lo que le da ventaja para capturar mayor parte de los dividendos asociados a la certificación. Esta situación, por tanto, expresa un problema ético y un punto de conflicto entre la ganancia y la responsabilidad del certificador, con aquello que dice certificar (Barry, 2017).

Debido a los riesgos asociados al poder de negociación de los certificadores, resulta de suma importancia la persistencia de la solidaridad y la confianza como principios rectores en el proceso de certificación. El CJ nace como una alternativa al mercado convencional; si este deja que los mecanismos de mercado, por sí solos, guíen su funcionamiento, comprometería su proyecto ético. En ese sentido, las particularidades de la certificación y su evolución constituyen una referencia obligada para monitorear la fidelidad a los principios éticos, o bien, para señalar sus inconsistencias. 


\section{Etiqueta y proyecto político}

Es innegable que el CJ ha contribuido a la generación de "espacios de inclusión" para los pequeños productores; sin embargo, los dictados subjetivos de calidad actúan también como una fuerza de exclusión (González, Linck y Moguel 2003). Aquellos productores sin suficiente calidad son precisamente los más pobres en recursos y dotaciones naturales y, por tanto, no se encuentran en condiciones favorables para incorporarse al CJ. A esta situación hay que agregar que, aun cumpliendo con los estándares de producción y calidad, los productores se enfrentan a una estructura institucional sofisticada que puede no ser sostenible en el largo plazo para las organizaciones (Goodman, 2004).

Para el enfoque institucionalista, dentro del movimiento de CJ existen dificultades para garantizar la compatibilidad entre la coordinación cívica y el mercado. Es decir, existe una tensión preocupante entre dos visiones: una que concibe el CJ como medio capaz de modificar el modelo económico dominante, y otra que prioriza una mayor apropiación de la demanda a costa de los valores éticos que se reivindican.

En el primer grupo, vinculado política e ideológicamente a movimientos militantes, la etiqueta es una herramienta identitaria, y el desafío consiste en transformar la manera en que se establecen las reglas del comercio. Por otro lado, el segundo grupo intenta apropiarse de un mayor segmento de la demanda y así tener una mayor incidencia en el fortalecimiento de las organizaciones de productores del sur, lo que demuestra por esta vía que el modelo dominante no es monolítico (Raynolds, 2000; Renard, 2003). La presencia de ambos proyectos refleja la lucha de dos posiciones políticas que, si bien han coincidido en el CJ, ello no significa que coexistan armoniosamente.

Inicialmente, en el CJ las personas aceptan abandonar sus cálculos y expectativas de reciprocidad económicas para comprometerse con los pequeños productores en una relación desinteresada. Posteriormente, el CJ ha recurrido a estrategias comerciales para permanecer en el mercado como la estandarización de criterios para la construcción de una marca, la implementación de procesos de control de calidad, y la separación entre los productores y los intermediarios. De esta suerte, las acciones que emprendieron para diferenciarse del mercado convencional se han ido adecuando con miras a extender los mercados y llegar a un mayor número de consumidores (Espinosa, 2017).

En consecuencia, el CJ presenta un importante dilema: la dualidad entre el incremento de las ventas y el poder de negociación de las organizaciones productoras. Esta disyuntiva, a la luz de la evolución misma del CJ, ha significado una separación de las raíces éticas, políticas y culturales con las que surgió el movimiento y que a posteriori ha justificado abrir las puertas a los grandes consorcios alimenticios.

\section{¿Quiénes ganan con las estrategias de marketing?}

El pletórico crecimiento de la riqueza y de la influencia cultural de las empresas multinacionales tiene su origen en una idea única: las empresas de éxito deben producir marcas y no productos. El carácter innovador de esta estrategia consiste en que las empresas crean y construyen modos de vida y códigos visuales mediante la creación de marcas, pero a "imagen y semejanza" de sus intereses empresariales. Ello deriva en la transición de una imagen abstracta al renombre de una marca y, con ello, a una insoslayable vía para generar alta valorización de las empresas (Klein, 2002).

En tal sentido, el incremento de las ventas se convirtió en una estrategia central del CJ y se asumió como el medio más eficiente para incidir en las condiciones de vida de los cafeticultores que participaban en el dispositivo. Paradójicamente, esta estrategia conlleva soslayar el principal objetivo del CJ, e implícitamente refleja una visión asistencialista en la que, entonces, el objetivo sería aminorar, atenuar, pero no cuestionar el origen de la pobreza.

Por otro lado, la saturación rápida del nicho de mercado es una limitante persistente en la venta de café solidario; esta restricción inicialmente se resolvió con la apertura de puntos de venta masivos, léase grandes cadenas comercializadoras, y con ello se profundizaron aún más las inconsistencias existentes. 
Por consiguiente, el CJ empezó a tomar decisiones que solo se sustentaron en las necesidades del mercado. Fue así como se incorporaron empresas como Nestlé y McDonald's, caracterizadas por sus prácticas depredadoras en el mercado convencional. Esta decisión causó fuertes tensiones y debates en el interior del CJ, en tanto que se interpretó como una forma de limpiar la mala imagen empresarial asociada a las grandes transnacionales (Puente Europa, 2006).

El debate permanece, las posiciones más conciliadoras apuntan a la posibilidad de negociar con los grandes consorcios. Consideran que es posible construir patrones de gobernanza a nivel macro con relaciones comerciales globales impulsadas por los compradores, aun con la presencia de grandes consorcios. Desde una perspectiva política, las relaciones comprador/proveedor del CJ están abiertas a la generación de pactos y se pueden establecer arreglos institucionales para controlar y monitorear a las empresas (Raynolds, 2009).

En una posición más crítica se encuentran quienes afirman que estos grandes consorcios no solo se han incorporado al dispositivo de coordinación del CJ, sino que se han infiltrado en el seno de los órganos de gestión y acomodan las reglas del juego a sus intereses. La participación de las grandes empresas agroalimentarias en el CJ y la certificación de productos orgánicos ha gestado un proceso de cooptación mediante la incursión de grupos de interés en los órganos de decisión y gestión, definiendo las agendas de los organismos certificadores y la utilización de estrategias para disminuir los niveles de exigencia en los estándares a favor del capital a gran escala (Jaffe y Howard, 2010).

Una visión más severa afirma que FLO se ha convertido en un enorme aparato burocrático donde priman intereses poco claros, y sobre todo de corto plazo. La visión estratégica de esta organización se ha alejado profundamente de los principios originarios del CJ; mediante la degradación de sus estándares, ha ampliado de manera visible el espectro de acción del movimiento y ha incluido en sus filas a actores ajenos como los grandes supermercados globalizados o las plantaciones (Coscione, 2013).
La participación de los grandes consorcios tiene riesgos importantes. El rol de las exportadoras transnacionales ha cambiado significativamente. Ha transitado de la simple distribución a una creciente injerencia en la exportación, la selección y el control de calidad del café desde los países de origen. Esto se traduce en una competencia desleal y en un repliegue, en términos de participación, de las organizaciones de pequeños productores que exportan el café de forma directa a los países consumidores. Las pugnas entre los pequeños productores y las grandes trasnacionales siguen presentes en las regiones cafetaleras. Las organizaciones cafeticultoras han expresado su inconformidad por la incorporación de grandes empresas al CJ y, a la par, han externado la posibilidad de construir sus propios canales colectivos de distribución para llegar al consumidor y eliminar la injerencia de las transnacionales (Pruijn, 2008).

De forma simultánea, a las transformaciones previamente mencionadas se suma un fenómeno en particular preocupante: la lightización del CJ de café. Este fenómeno se encuentra concatenado a un problema más amplio: el dominio de las marcas a nivel global, tal como lo señala Klein (2002). Esta misma lógica es apropiada por los pequeños productores, que se han lanzado a la construcción de un nuevo sello que sirva realmente a sus intereses.

\section{Símbolo de Pequeños Productores (SPP): una alternativa o ¿̇a' qué tanto brinco, estando el suelo tan parejo?}

Una de las principales salidas a las inconsistencias presentes en el CJ se concretizó en la creación de la etiqueta Símbolo de Pequeños Productores (SSP) en 2006, respaldada por varias organizaciones de pequeños productores agremiados en la Coordinadora Latinoamericana y del Caribe de Pequeños(as) Productores(as) y Trabajadores(as) de Comercio Justo (CLAC) (ver Figura 2). ${ }^{11}$

El SPP, en su declaración de principios (SPP, 2011), plasma aquello que dirige al sello y a las organizaciones afines. Los principios y valores que refrenda el SPP 
fueron desarrollados y promovidos por una variedad de campesinos, indígenas y artesanos rurales, en América Latina, el Caribe y en otros continentes. Esencialmente se reivindican valores como la solidaridad, entendida como la base de la organización social y en contraposición al egoísmo y la indiferencia. También se refrenda la justicia como base ética para la generación de reglas democráticas y sin discrecionalidad entre las organizaciones que participan. De igual forma, la confianza juega un rol importante al comprometer a los integrantes de una organización a un trato entre pares con responsabilidad, lo que permite a su vez generar relaciones sociales y de intercambio a largo plazo.

Además, reivindican la producción a pequeña escala en contraposición con la empresa a gran escala, que provoca el desempleo masivo a través de la competencia desigual. Se defiende la comercialización directa como un mecanismo que permite generar valores locales más sólidos y fortalecer la economía familiar. De igual forma, proponen entender la calidad como la cristalización de acuerdos entre las partes interesadas, y también como una serie de cualidades reconocidas económicamente en el mercado.

La etiqueta SPP representa una alianza entre pequeños productores con el propósito de construir un mercado local y global que valorice la identidad y las aportaciones económicas, sociales, culturales y ecológicas de las organizaciones de pequeños productores. En los mercados locales y globales, el SPP permite diferenciar los productos de los pequeños productores, de aquellos manufacturados por las grandes empresas (SSP, 2019).

El sello se encuentra amparado por un sistema de certificación independiente. La etiqueta garantiza al consumidor que los productos son hechos por auténticas organizaciones democráticas de pequeños productores. Asimismo, avala que el producto se elaboró con total apego a criterios de sustentabilidad económica, social, cultural y ecológica, y que se comercializa bajo condiciones justas (SSP, 2019).

En el SSP, las instancias que se certifican son las organizaciones de pequeños productores. En el caso de los compradores, intermediarios, maquiladores y comer- cializadores colectivos de organizaciones de pequeños productores, se registran; para ambos casos se realizan cotizaciones y se paga un monto anual de acuerdo con el volumen de producción o superficie.

La certificación es realizada por instancias autorizadas por SPP Global para operar el Programa de Certificación y Registro del Símbolo de Pequeños Productores. Todas las certificadoras autorizadas SPP cuentan con acreditación ISO 65 o equivalente. Instancias certificadoras como la Certificadora Mexicana de Productos y Procesos Ecológicos (CERTIMEX), Maya Cert Organic e IMOcert, entre otras, están acreditadas para realizar las auditorías (SPP, 2019).

En términos políticos, la importancia del SPP radica en la reivindicación del protagonismo de los pequeños productores como actores que dirigen el proceso de producción, comercialización y certificación. De esta forma, las organizaciones productoras son parte activa en los procesos de negociación de sus propios productos.

El surgimiento del SPP ha sido interpretado como la respuesta organizada de los pequeños productores, derivada de la naturaleza burocrática de FLO, en tanto que dicho organismo se ha centrado más en garantizar la trazabilidad del producto a través de procesos de supervisión externa, que en generar condiciones para brindar una posición de negociación más favorable a los pequeños productores. Si bien el SPP funciona a través de verificaciones mediante terceros, la forma en que se organiza se caracteriza porque los productores tienen un mayor control social, lo que ha evidenciado la posibilidad de democratizar el proceso de certificación. La experiencia del SPP invita a reflexionar sobre la posibilidad de democratizar tanto el CJ, como otros modelos de certificación, particularmente con el objetivo de equilibrar la participación de los actores en los procesos de supervisión interna y externa en sistemas de certificación con múltiples partes interesadas (Clark y Hussey, 2016).

Igualmente, el SPP contribuye a cuestionar la opinión generalizada que sostiene que el proceso de certificación pierde rigor de imparcialidad en la medida que existe mayor proximidad entre quien certifica y el actor que demanda la certificación. Es decir, se 
asume que cuanto mayor sea la distancia entre quien produce y quien certifica existe una mayor garantía de imparcialidad y objetividad (Renard y Loconto, 2012). Este discurso sostiene la legitimidad de los modelos de certificación, y particularmente la certificación de CJ, los cuales se presentan como objetivos y desinteresados. No obstante, como se ha señalado, en la práctica no es imparcial en tanto que existen diferencias en el poder de negociación de los actores que participan en la certificación.

A la par, existe una relación compleja entre el SPP y el CJ, en tanto que las organizaciones productoras agremiadas en la CLAC, red regional del CJ, colaboraron de forma activa en la creación del SPP. No obstante, esas mismas organizaciones permanecen en el CJ y lo reivindican como un proyecto vigente. De hecho, durante su VI Asamblea General en el año 2017, las organizaciones productoras aglutinadas en el SPP lanzaron un llamado para rescatar el CJ y cuestionar los rumores respecto a su desaparición como proyecto, y en su lugar proponer "sanearlo de todos sus males" y hacer un llamado a no permitir que, como organizaciones protagonistas, las despojen del CJ (SPP, 2017).

Por otro lado, la actividad cafetalera en Chiapas es de vital importancia porque es el medio de vida de una cantidad importante de productores indígenas. Cerca de 180000 familias, distribuidas en 88 municipios, viven de la producción del aromático. En la entidad se ubican aproximadamente 180856 productores de café, de los cuales cerca del $61 \%$ son indígenas; dichos cafeticultores poseen cerca de 253764 hectáreas destinadas a la producción de café (Instituto del Café de Chiapas, 2019).

Aunado a lo anterior, la producción de aromático cobra una mayor relevancia dadas las tendencias favorables presentes en el mercado internacional respecto a los productos agroalimentarios certificados. Históricamente las organizaciones cafetaleras chiapanecas han incursionado en los nichos de mercado como el CJ, orgánico y de especialidad. Aun con las dificultades que han enfrentado los cafeticultores en estos nichos, es justamente a partir de ellos como han logrado desarrollar y mejorar sus capacidades productivas y de comercialización.
En el caso de Chiapas, cerca de diez organizaciones cafeticultoras cuentan con la certificación SPP, entre las que se encuentran: Unión Majomut, Campesinos Ecológicos de la Sierra Madre de Chiapas (CESMACH), Comunidades Indígenas de la Región de Simojovel de Allende (CIRSA), Finca Triunfo Verde, Unión de Ejidos y Comunidades San Fernando. Y a nivel nacional, organizaciones históricas como la Coordinadora Estatal de Productores de Café del Estado de Oaxaca (CEPCO), la Unión de Comunidades de la Región del Istmo(UCIRI) y Tosepan Titataniske ostentan el sello (SPP, 2019). Buena parte de estas organizaciones, pioneras en elCJ, fungieron como colaboradoras en la conformación del sello SPP.

El SPP se ha interpretado como un hito en la democratización de los procesos de certificación; sin embargo, en la práctica existen matices que se hace necesario señalar. Un asunto relevante en estos esquemas de certificación son sus altos costes económicos. Al igual que en el CJ, el costo de la certificación es potencialmente una fuerza excluyente de los productores más pobres. Si bien en los hechos los productores cumplen con los requerimientos, estos deben pagar la certificación SPP para validar sus prácticas.

Por otro lado, a las organizaciones que obtienen la certificación no necesariamente se les garantiza la venta del producto. Existen ya experiencias de organizaciones en Los Altos de Chiapas que no lograron vender su producto certificado porque no hubo comprador, y, en consecuencia, al año siguiente optaron por no certificarse. En suma, para las organizaciones es redituable tener la certificación si existe un comprador concertado; de lo contrario, corren el riesgo de quedarse con su producto.

En Chiapas se desarrolló una rápida proliferación de cooperativas de pequeños productores de café, orientados principalmente a la producción de café orgánico certificado, que comenzaron a exportar a través del CJ. El desarrollo de las cooperativas ciertamente ha contribuido a promover una opción económica para los pequeños productores; sin embargo, esta alternativa presenta importantes retos para los productores. Existen experiencias en la entidad de cooperativas que no pudieron superar el proceso de certificación y eventualmente desaparecieron (Folch y Planas, 2019). 


\section{Conclusiones}

A lo largo del texto se han expresado diversas posiciones sobre el estado actual del CJ y las expectativas sobre el SPP, pero iqué decimos nosotras? Nuestra posición es que dicho sello corre el riesgo de seguir el mismo camino que actualmente transita el CJ porque repite la dependencia a una certificación externa. Aunada a esto se encuentra su fragilidad por la falta de recursos financieros y de experiencia que permitan posicionar el sello en términos de venta al público.

Por otra parte, nuestro trabajo de campo exploratorio con las organizaciones chiapanecas que ostentan este sello ha mostrado la coexistencia de diferentes visiones intergeneracionales de los socios de las organizaciones cafetaleras. Por un lado, para los socios que participaron en la fundación de las cooperativas, la participación en el CJ, y en el propio SPP, forma parte de un proceso de lucha y organización que reivindica su condición de pequeño productor e indígena; sin embargo, para las nuevas generaciones el CJ, el SPP y la certificación orgánica forman parte de una estrategia comercial "multisello" para consolidarse en el mercado.

Finalmente, al margen de sus transformaciones, el CJ ostenta el mérito de colocar en la mesa de debate la necesidad de cuestionar y repensar los valores movilizados en las relaciones comerciales basadas en la maximización de la ganancia, y que dejan de lado el desarrollo de capacidades y empoderamiento de los pequeños productores. También resulta significativo señalar que tanto la solidaridad como la confianza se confrontan con la lógica de la ganancia y con el pensamiento productivista y competitivo que caracteriza al mercado. Por ende, existe una pugna entre los actores que reivindican dichos valores éticos y aquellos que pretenden despojar a esta forma de comercializar de su contenido ético y político.

\section{Notas}

${ }^{1}$ Los países productores exportan básicamente café oro, a partir del cual se inicia la torrefacción. Esta fase última ha sido considerada como la que confiere las cualidades gustativas definitorias del aromático a partir de su tueste y mezcla de granos por su origen u otras características. Por ello, no es fortuito que los grandes consorcios cafeteros se reserven esta fase del procesamiento, no solo para generar calidad gustativa, sino fundamentalmente para tener el control sobre la especulación comercial del café.

2 Trabajo de campo de la primera autora con las organizaciones Maya Vinic, Tzeltal-Tzotzil y Majomut, realizado durante el periodo de febrero de 2017 a diciembre de 2018.

${ }^{3}$ Las autoras llevan a cabo una investigación de largo alcance sobre las redes alternativas de comercialización en México, y en particular en Chiapas. Por ello, conciben su participación en estos espacios de discusión de manera activa.

${ }^{4}$ La certificación de CJ se aplica a la cosecha de una superficie dada y se concreta con el derecho mercantil de utilizar el logo sobre el volumen de producción estimado al momento de hacer la inspección de campo y únicamente para ese ciclo de producción. De hecho, cualquier tipo de certificación se ampara en estrictos mecanismos de trazabilidad, capaces de rendir cuentas y certidumbre sobre el producto que ostenta el logo o símbolo en su etiquetado final.

${ }^{5}$ Los trabajos de Naomi Klein (2002) son sin duda una forma de aproximarse a la forma en que el logo se ha convertido en una estrategia de mercadeo, afianzada en la movilización de emociones, sentimientos o adhesiones que movilizan distintos valores o expectativas del querer ser a través del acto de compra.

${ }^{6}$ Texto citado en diversos sitios web dedicados a la obra del autor, retomado de su obra Patas arriba. La escuela del mundo al revés.

${ }^{7}$ Nuestra reflexión sobre el don en este artículo ha sido posible gracias a las sugerencias de nuestros dictaminadores. El tema abre sin duda un campo socioantropológico y teológico aún poco discutido en la literatura sobre CJ.

${ }^{8}$ Utilizamos el término sur para expresar la existencia de sociedades que comparten una historia común de pasado colonial y de la consideración de su nivel de desarrollo. El término no remite a definiciones geográficas. A su vez, el sur se construye en contraposición al norte, entendiendo este como las sociedades que por sus características económicas y predominancia políti- 
ca controlan la agenda mundial en materia económica, política, social y cultural.

${ }^{9}$ Ciertamente, existe un amplio debate respecto a la relación entre comercio, crecimiento económico y desarrollo. En particular, nosotras retomamos el término "comercio para el desarrollo" para expresar la generación de relaciones comerciales como un medio para detonar procesos de desarrollo económico y justicia social, tal y como lo planteó en sus inicios la Conferencia de las Naciones Unidas sobre Comercio y Desarrollo (UNCTAD, por sus siglas en inglés).

${ }^{10}$ Las cooperativas de productores se integran en tres bloques regionales: 1) Coordinadora Latinoamericana de Comercio Justo (CLAC), 2) Fair Trade Africa y 3) Network of Asian Producers.

${ }^{11}$ Si bien el artículo no se centra en las cualidades gráficas del SPP, resulta importante preguntarse sobre las posibilidades que tiene el sello para competir con otros y penetrar la psique del consumidor.

\section{Referencias}

Auroi, Claude (2006). "El comercio justo frente a la mundialización: ipermanecer en su nicho o moralizar el gran comercio?" En Puente Europa, 4(2), junio, 21-25.

Barry, Ibrahima (2017). Essais sur la certification des biens de confiance : une analyse théorique et empirique des marchés en asymétrie d'information. Tesis doctoral, Universidad de Grenoble, Francia.

Caswell, Julie A. y Eliza M. Mojduszka (1996). "Using informational labeling to influence the market quality in food products". En American Journal of Agricultural Economics, 78(5), 1248-1253.

Clark, Patrick e Ian Hussey (2016). "Fair Trade Certification as Oversight: an Analysis of Fair Trade International and the Small Producer's Symbol". En New Political Economy, 21(2), septiembre, 220-237.

CLAC (Coordinadora Latinoamericana y del Caribe de Pequeños Productores de Comercio Justo) (2011). "Declaración de la CLAC frente a la nueva visión del Comercio Justo y salida de FT USA de FLO". Disponible en http://clac-comerciojusto.org/wp-content/ uploads/2015/04/2011-Declaraci\%C3\%B3n-de-la-
Coordinadora-Latinoamericana.pdf (consultado el 5 de marzo de 2017).

Coscione, Marco (2013). "América Latina reescribe el sentido del Comercio Justo certificado: un desafío para las ciencias sociales de la región". En Otra Economía. Revista Latinoamericana de Economía Social y Solidaria, 6(11), julio-diciembre, 134-140.

Doppler, Flurina y Alma Amalia González (2007). "El comercio justo: entre la institucionalización y la confianza". En Problemas del Desarrollo, 38(149), 181-202. Disponible en http://www.revistas.unam.mx/index. php/pde/article/view/7658/7147 (consultado el 21 de abril de 2020).

Espinosa, Betty (2017). Las redes del comercio justo. Interacción entre el don y el intercambio comercial. Quito: FLACSO-Ecuador.

Faircompanies (2007). "Sobre la organización de comercio alternativo (ATO)”. Disponible en https://faircompanies.com/articles/sobre-la-organizacion-de-comercioalternativo-ato (consultado 14 de diciembre de 2017).

Fairtrade International (2009). "Carta de los principios del Comercio Justo". Disponible en https://wfto.com/ sites/default/files/Charter-of-Fair-Trade-PrinciplesFinal\%20(SP).PDF (consultado el 19 de abril de 2020).

Fairtrade International (2017). "General Assembly and Board". Disponible en https://www.fairtrade.net/aboutfairtrade/fairtrade-system/board-members-general-assembly.html (consultado el 1 de marzo de 2018).

Fairtrade International (2019). "Historia de Fairtrade". Disponible en https:/www.fairtrade.net/es/aboutfairtrade/history-of-fairtrade.html (consultado el 5 de octubre de 2019).

Folch, Albert y Jordi Planas (2019). "Cooperation, Fair Trade, and the Development of Organic Coffee Growing in Chiapas (1980-2015)". En Sustainability, 1l(22), enero, 1-22.

Gendron, Corinne (2001). "Émergence de nouveaux mouvements sociaux économiques". En Revue Pour (172), 175-181.

Gendron, Corinne (2008). “El Comercio Justo: un nuevo movimiento social económico en el corazón de otra globalización". Montreal: Chairé de responsabilité sociale et de développement durable ESG UQÁM. 
Gendron, Corine, Véronique Bisaillon y Ana Isabel Otero Rance (2009). "The institutionalization of Fair Trade: More than just a degraded form of social action". En Journal of Business Ethics, 86(1), abril, 63-79.

González, Alma Amalia, Thierry Linck y Reyna Moguel (2003). "El comercio de valores éticos. Las reglas del juego del café solidario". En Revista Europa de Estudios Latinoamericanos y del Caribe, (75), octubre, 31-45.

Goodman, Michael (2004). "Reading fair trade: political ecological imaginary and the moral economy of fair-trade foods". En Political Geography, 23(7), septiembre, 891-915.

Instituto del Café de Chiapas (2019). "Datos importantes del café". S/l: INCAFECH. Disponible en https://incafech.gob.mx/assets/media/documentos/Datos\%20 cafe.pdf (consultado el 27 de enero de 2020).

Jaffe, Daniel, y Philip H. Howard (2010). "Corporate Cooptation of Organic and Fair-Trade Standards". En Agric Hum Values, 27(4), julio, 387-399.

Klein, Naomi (2002). No logo: el poder de las marcas. Madrid: Paidós Ibérica.

Kocken, Marlike (2014). "Sixty Years of Fair Trade.”. Bruselas: World Fair Trade Organization. Disponible en https://wfto-europe.org/sixty-years-of-fair-trade/ (consultado el 21 de abril de 2020).

Low, Will y Eileen Davenport (2006). "Mainstreaming Fair Trade: Adoption, Assimilation, Appropriation”. En Journal of Strategic Marketing, 14(4), diciembre, 315-327.

Malservisi Mauro F. e Isabel Faubert-Mailloux (2000). "Le commerce équitable". En Chaire de coopération Guy-Bernier, núm. 006-112. Montréal : ESG UQÁM.

Mauss, Marcel (2009[1924]). Ensayo sobre el don: forma y función del intercambio en las sociedades arcaicas. Buenos Aires: Katz. Disponible en http://mastor.cl/blog/wp-content/ uploads/2017/05/MAUSS-Marcel-Ensayo-sobre-eldon-1924.pdf (consultado el 10 de mayo de 2020).

Micheletti, Michele (2003). Political virtue and shopping: individuals, consumerism, and collective action. Nueva York: Palgrave MacMillan.

Nigh, Ronald y Alma Amalia González Cabañas (2015). "Reflexive consumer Markets as Opportunities for a new peasant farmer in Mexico and France: constructing food sovereignty through Alternative Food
Networks". En Agroecology and Sustainable Food Systems, 39(3), marzo, 317-341.

Otero, Ana Isabel (2006). "El comercio justo como innovación social y económica: el caso de México”. En La chronique des Amériques, 35. Québec: Centre Études internationales et Mondialisation. Disponible en https://archipel.uqam.ca/9974/

Puente Europa (2006). "Entrevista a Frans Van der Hoff". En Puente Europa, 4. Disponible en: https://issuu.com/ puntoeuropa/docs/puente_europan2_2006 (consultado el 17 de abril de 2020).

Pruijn, Jerónimo (2008). "Trasnacionales ante el mercadeo alternativo". En La Jornada, 12 de junio, 9.

Raynolds, Laura (2000). "Re-embedding Global Agriculture the International Organic and Fair-Trade Movements". En Agriculture and Human Values, 17(3), enero, 297-309.

Raynolds, Laura (2009). "Mainstreaming Fait Trade Coffee: From Partnership to Traceability”. En World Development, 37(6), junio, 1083-1093.

Renard, Marie-Christine (2003) "Fair Trade: Quality, Market and Conventions". En Journal of Rural Studies, 19(1), enero, 87-96.

Renard, Marie-Christine y Allison Loconto (2013). "Competing Logics in the Further Standardization of Fair Trade: ISEAL and The Símbolo de Pequeños Productores". En International Journal of Sociology of Agriculture $\sim$ Food, 20(1), junio, 51-68.

Roch, Lysiane y Valérie Demers (2007). "Nouveaux mouvements sociaux économiques et développement durable: les nouvelles mobilisations à l'ère de la mondialisation". En Natures Sciences Sociétés, 15(3), eneromarzo, 91-92.

SPP (Símbolo de Pequeños Productores) (2011). "Principios y valores". México: SPP. Disponible en https:// spp.coop/el-spp/principios-y-valores/ (consultado el 15 de julio de 2018).

SPP (Símbolo de Pequeños Productores) (2017). "Declaración y llamado urgentes por el rescate del CJ". México: SPP. Disponible en https://spp.coop/ wp-content/uploads/2017/07/Declaraci\%C3\%B3nLlamado-Comercio-Justo_VI-AG-SPP-2017_201706-29_P\%C3\%9ABLICO.pdf (consultado el 15 mayo de 2018). 
SPP (Símbolo de Pequeños Productores) (2019). "¿Qué es el SPP?" México: SPP. Disponible en https://spp.coop/ el-spp/que-es-el-spp/ (consultado el 16 de mayo de 2019)

Temple, Dominique (1983). La dialectique du don. Essai économique des communautés indigènes. París: Association Diffusion Inti.
Touraine, Alain (1994). Crítica de la modernidad. México: Fondo de Cultura Económica.

Zeithaml, Valarie (1981). "How consumers evaluation processes differ between goods and service". En James H. Donelly y William R. George (coords.), Marketing of services. Chicago: American Marketing Association, pp. 186-190.

Figura 1. Etiqueta Comercio Justo

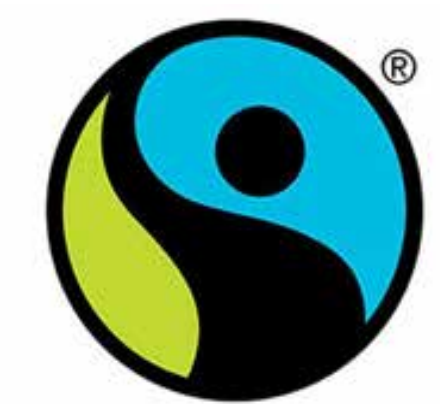

\section{FAIRTRADE INTERNATIONAL}

Fuente: Fairtrade International (2019).

Figura 2. Etiqueta del SSP

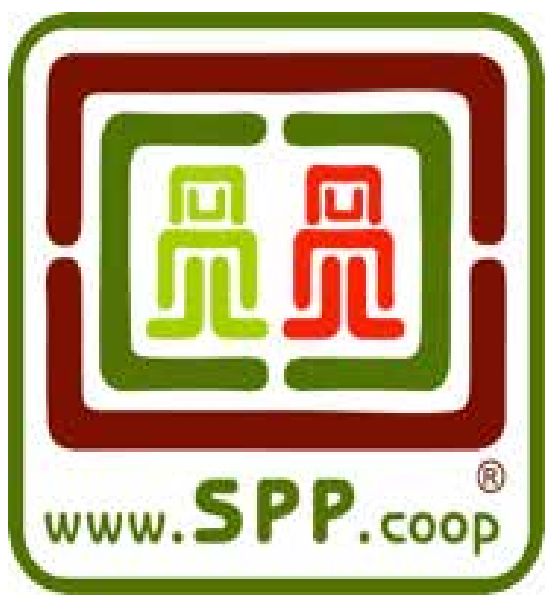

Fuente: SSP (2019). 